\title{
Study of Chemical Neurolysis, Radiofrequency Ablation and Combined Radiofrequency with Chemical Neurolysis of Lumbar Sympathetic Ganglion in Peripheral Vascular Diseases of the Lower Limbs
}

\author{
Kalpana R Kulkarni* ${ }^{1 *}$ and Rajendra M Kulkarni ${ }^{2}$ \\ ${ }^{1}$ Prof. \& HOD (Dept. of Anaesthesia and Pain Management), DY Patil Medical College, Kolhapur MH, India \\ ${ }^{2}$ Prof. \& HOD (Dept. of Surgery), DY Patil Medical College, Kolhapur MH, India
}

*Corresponding author: Kalpana R Kulkarni, Prof \& HOD (Dept. of Anaesthesia and Pain Management), DY Patil Medical College, Kolhapur MH, India

\begin{abstract}
Background: Peripheral vascular diseases (PVDs) associated with atherosclerosis, hypertension, diabetes, thromboembolism, chronic regional pain syndrome or Berger's disease, presents with ischemic manifestations of cold limbs, claudication, ulcers, or gangrene. Chemical lumbar sympathetic block (LSGB) with alcohol/ phenol and radiofrequency ablation (RF) are well-established methods to improve the circulation.

Methods: We conducted prospective observational study in 150 cases of PVDs who underwent chemical LSGB using $5 \mathrm{ml}$ of phenol 8\% at two levels L2 and L3 under guidance of fluoroscopy (Group CH, n=50), RF ablation of lumbar sympathetic ganglions at L2 and L3 level (Group RF, $\mathrm{n}=50$ ) and combined RF with chemical LSGB using phenol $5 \mathrm{ml}$ 8\% at L2and L3level following RF(Group $\mathrm{RF}+\mathrm{CH}, \mathrm{n}=50)$.

Results: There was significant difference in VAS scores at six months of follow up in Group CH Vs Group RF+CH and Group RF Vs Group RF+CH, (mean VAS 2.2 in Group CH, 1.94 in Group RF \& 1.26 in Group RF+CH,P $<0.001$ ) The mean WD improved significantly at six months in Group RF and $\mathrm{RF}+\mathrm{CH}$ when compared with Group $\mathrm{CH}(\mathrm{P}<0.001)$. At six months the temperature rise in affected limb/toe noted was 2.6 in Group $\mathrm{CH}, 2.76$ in Group $\mathrm{RF}$ and $2.76{ }^{\circ} \mathrm{C}$ in Group $\mathrm{RH}+\mathrm{CH}$, it was significant for Group $\mathrm{CH}$ Vs $\mathrm{RF}+\mathrm{CH}$, $\mathrm{P}<0.05$.

Conclusion: We observed significant reduction in VAS score, increase in WD and rise in temperature of the limb in all the groups, but longer lasting effects seen in combined technique in Group RF+CH as compared to sole RF or chemical LSGB.

Keywords: Gangrene, Peripheral vascular diseases, Lumbar sympathetic ganglion block, Chemical neurolysis, Radiofrequency ablation
\end{abstract}

\section{Introduction}

Lumbar sympathectomy is indicated for the treatment of intermittent claudication or rest pain in legs due to ischemia of Buerger's disease, chronic regional pain syndrome (CRPS) type I,II, thromboembolic phenomena, diabetic ulcers, diabetic neuropathic pain, acute herpes pain, Paget's disease of bones, hyperhidrosis, chronic pancreatitis and malignant visceral pain. Buerger's disease is an inflammatory disorder affecting medium sized vessels and adjacent nerves where tobacco plays key role for the disease process. Major presenting symptoms are moderate to severe pain in the limbs, affection of sleep and significant work disability. On Doppler ultrasonography there is reduced/absent flow in peripheral arterial system usually in iliofemoral, popliteal, tibialis posterior and dorsalis pedis artery in patients with ischemic lower limb. Lumbar sympathetic ganglia are present from L2 to L5 paravertebral region where blocking of L2-L3 ganglia blocks the sympathetic fibres of the lower extremities and produces vasodilatation. There are surgical and nonsurgical options available for the treatment of ischemic pain and non-healing ulcers. 
Surgical sympathectomy causes lot of trauma and tissue damage, chemical sympathectomy may harm surrounding vital tissue due to drug diffusion but still popular method of neurolysis. LSGB with local anaesthetics (LA) or with adjuvants like alpha 2 agonists clonidine, opioids, NMDA receptor antagonist ketamine, steroids or Botox are used to prolong the pain-relieving effects. A diagnostic LSGB with LA followed by neurolysis of lumbar sympathetic chain is safe and useful method over invasive operative procedure [1,2]. During1930s-1950s chemical lumbar sympathectomy was widely used in treating occlusive arterial disease of the lower limbs as an alternative to amputation [3]. Sympathetic denervation results in increased blood flow, improves the collateral circulation and nutritive value of blood flow and thus decreases the pain transmission. [4,5] Currently RF ablation of LSG is safe and effective option that is gaining popularity for lesser incidence of complications but have concerns of high cost and availability. There are reports of the use of combined methods in the literature but very few studies are available [6,7]. We aimed to study and compare the efficacy of three techniques of LSGB i.e. chemical neurolysis, RF ablation and combined RF + chemical LSGB in successive 150 patients of PVDs. The primary outcome variables for the study were improvement in VAS score, WD and rise in temperature of the affected limb with secondary outcome to assess for immediate and late complications and progress in the wound healing up to six months proposed treatment.

\section{Material \& Methods}

After obtaining Institutional review board permission and Informed consent from the patients we conducted a prospective nonrandomized observational study on 150 patients of PVDs of lower limbs who underwent chemical LSGB (Group CH, n=50),RF ablation of LSG (Group RF, $\mathrm{n}=50$ ) and RF + chemical LSGB (Group $\mathrm{RF}+\mathrm{CH}, \mathrm{n}=50$ ) at our Institution over the period of six years ( 2014 to 2019).The inclusion criteria's were Buerger's disease ( having history of smoking, cold limbs, colour change of the skin, hyperhidrosis) with claudication ,gangrene of toes, nonhealing ulcers, atherosclerotic PVD, diabetic non healing ulcer or gangrene, chronic post thrombo-embolic vascular obstruction in lower limbs with ulcer or gangrene, scleroderma with gangrene of toes and patients with post amputation CRPS. To assess the circulation in the lower limb all were subjected to arterio-venous
Doppler study or CT angiography of the lower limbs and found to have reduced or absent flow in illeal-femoral or popliteal and anterior/posterior tibial and dorsalis pedis artery. Patients with acute embolic obstruction, extensive multiple ulcers with abscess or in sepsis with uncontrolled diabetes, on anticoagulant therapy were excluded for interventional management with LSGB. All the patients undergoing LSGB were evaluated and optimized as for any other surgical procedure. General investigations like CBC, blood sugar, urea, creatinine, ECG, and other specific investigations for associated co morbidities are done.

Pre and post block visual analogue score (VAS), walking distance (WD) in meters noted. Presence of arterial pulsations in femoral/ popliteal /posterior tibial and dorsalis pedis noted. Temperature (Temp.) of the affected limb and non-affected limb measured. The presence of gangrene /non-healing ulcer and discoloration of the limbs noted. Informed consent for the procedure was obtained following proper counselling of the patient and nil by mouth period of 6-8 hours was observed. Intravenous access for IV fluids and for anxiolysis midazolam $0.5-2 \mathrm{mg}$ with fentanyl $50 \mathrm{mcg}$ was given. Monitoring for the vitals like pulse, NIBP, ECG, $\mathrm{SPO}_{2}$ started. Procedure was performed in prone position and a pillow was placed below the abdomen to obliterate the lordosis. As described by Reid and co-workers [8] we followed the single needle technique of LSGB at L2 or L3 vertebral level in prone position. Under aseptic precautions LA infiltration was given just above or below the tip of transverse processes i.e. for lateral approach at 6-8cm away from the midline at level of L2 or L3.A22 G $15 \mathrm{~cm}$ long spinal needle was inserted under fluoroscopic guidance in AP view advanced till it hits the vertebral body. (Figure 1A) Then needle redirected and advanced fluoroscopy in LAT view until it reached the anterior border of the vertebral body. (Figure 1B) Following negative aspiration test $2 \mathrm{ml}$ of radio opaque dye (Iohexol, Omnipaque 300) was injected to confirm the needle position and test dose of LA lignocaine 1-2 \%, 3ml injected and observed for the subjective signs of pain relief and warmth in the limb (Figure 1) . Later $10-15 \mathrm{ml}$ of $0.25 \%$ bupivacaine injected slowly over 10 minute and patient was made supine. During and after the procedure patient was monitored for the vitals and for any side effects or complication for 30 minutes. Significant pain relief rise of temperature of the affected limb for at least $2-3^{\circ} \mathrm{C}$, anhidrosis, change of colour of the limb and vasodilatation was seen.
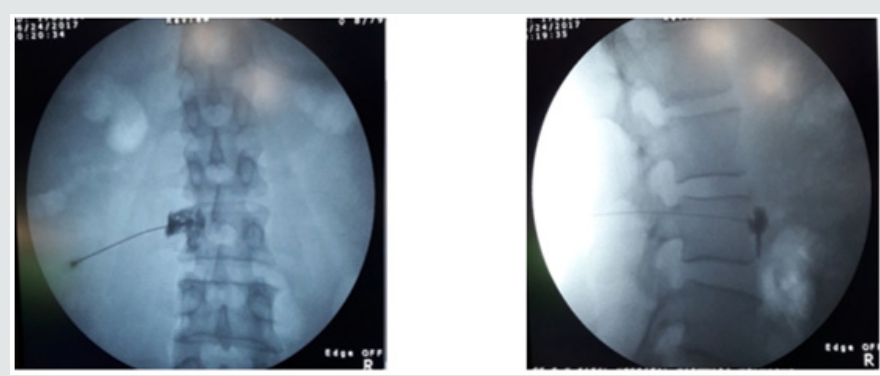

Figure 1: Figure 1A Single needle LSGB-AP view, Figure 1B-Single needle LSGB LAT view. 
The block was repeated with similar drugs and doses for four successive days to achieve maximum vasodilatation. For chemical neurolysis as described by Rauk, we used double needle method at L2 and L3 vertebral level. [2] On fifth day following injection of test dose of LA either $5 \mathrm{ml}$ of $8 \%$ phenol was used for chemical neurolysis $(n=50)$ at two levels L2 \& L3. Half ml of air injected before removal of the needles and prone position maintained for half an hour to prevent posterior spread of solution and then patient made supine. RF (NeuroTherm 2000) lesion generator was available since 2015 for use at our Institution. There are studies regarding use of $\mathrm{RF}$ for sympatholysis, its comparison with chemical neurolysis with superior results with lesser complications. [9-13] Based on these studies we hypothesized that RF is a better alternative and aimed to study the efficacy of RF and of combined techniques i.e. RF with chemical LSGB using $8 \%$ phenol. Thus next patients $(n=50)$ underwent RF ablation of LSG with two needle technique at L2, L3 level using $22 \mathrm{G} 15 \mathrm{~cm}$ RF Insulated needles having $10 \mathrm{~mm}$ active tip. Further we combined the technique of RF ablation with chemical LSGB $(n=50)$ with two needle technique L2 and L3 vertebral level. (Figure 2) Under fluoroscopy two RF needles were placed at the anterolateral border of L 2, L3 vertebra. After negative aspiration test the needles position again confirmed with $1 \mathrm{ml}$ of non-ionic contrast and its spread noted under fluoroscopy (Figure 3A, 3B). Sensory and motor testing attempted at L2 then L3 level with the active RF electrode by stimulation with $50 \mathrm{HZ}$ and $2 \mathrm{HZ}$ with $0.5 \mathrm{v}$ and $2 \mathrm{v}$ respectively to check the sensory and motor response. This was followed by the injection of test dose $2 \mathrm{ml}$ of LA lignocaine at each point. Rise of temperature of $1-2^{\circ} \mathrm{C}$ within $2-3$ minutes in the affected limb measured to confirm the block effect. $\mathrm{RF}$ ablation at L2 and L3 level was done at $80-90^{\circ} \mathrm{C}$ for $90-180 \mathrm{sec}$.

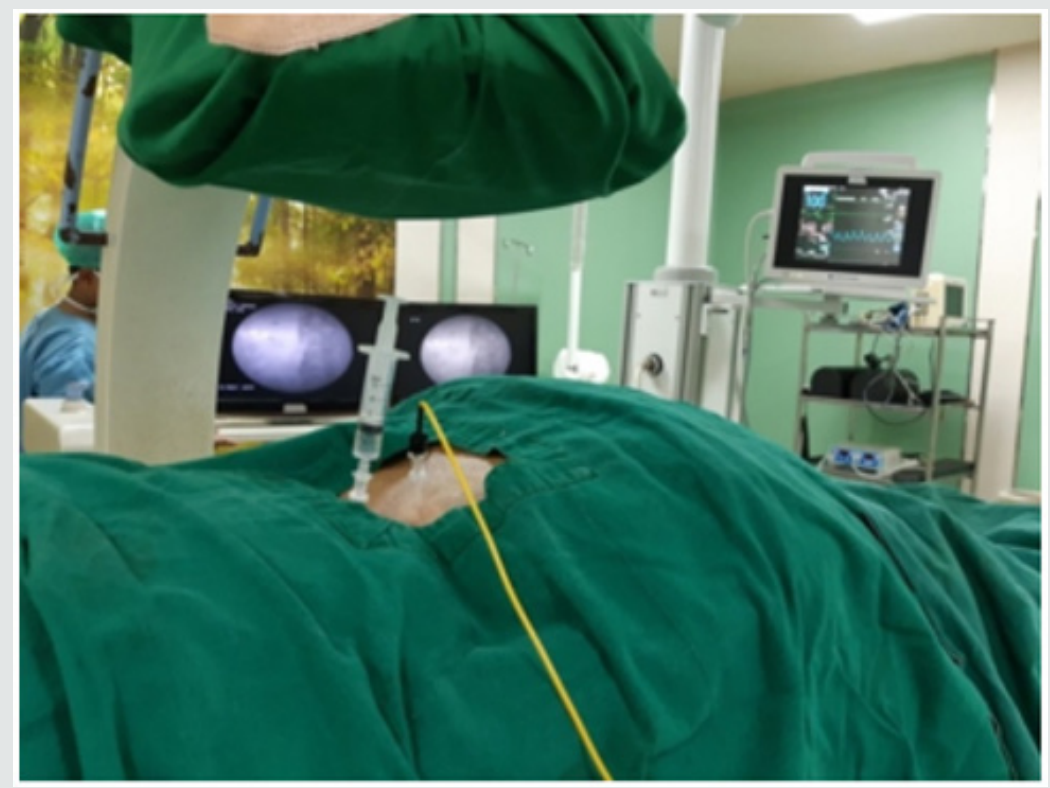

Figure 2: Technique of RF ablation + chemical LSGB with two needle technique.

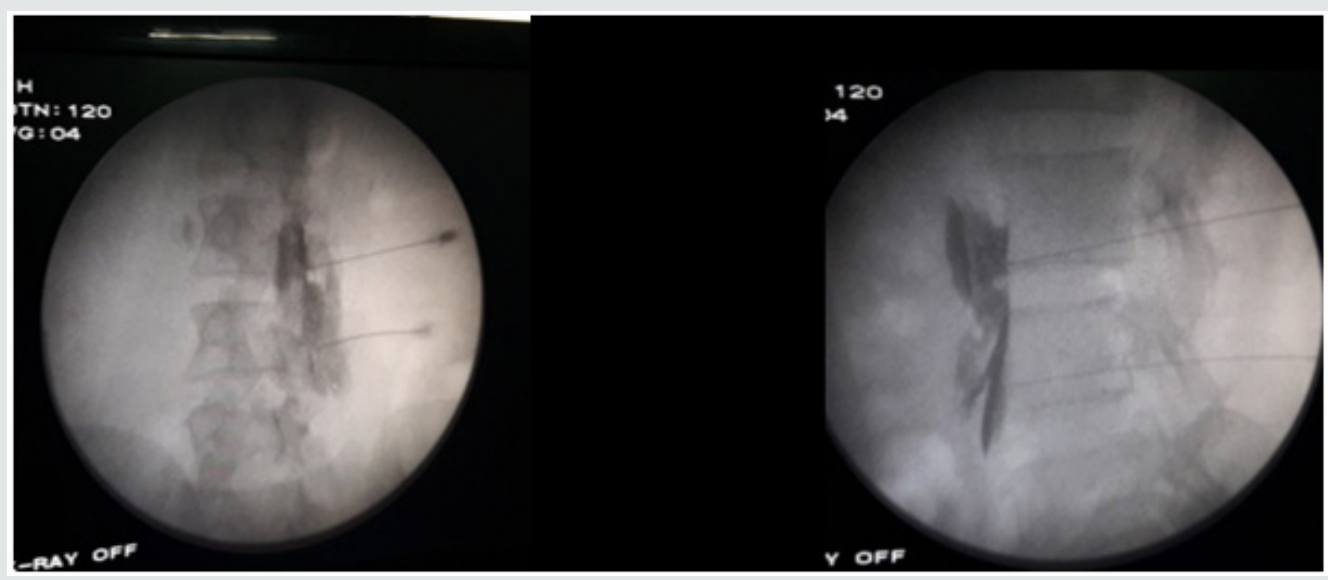

Figure 3: Figure 3A RF + Chemical LSGB with two needle technique AP view, Figure 3B RF + Chemical LSGB with two needle technique LAT view. 
Three such lesions were carried out by advancement of the tip for 2-5 mm. After initial RF treatment at L2-L3 level chemical neurolysis of LSG with $5 \mathrm{ml} 8 \%$ phenol was carried out at each level. Later half $\mathrm{ml}$ of air injected before removal of the needles and prone position maintained for half an hour. Post block sensory and motor functions were checked after each block in all the patients of LSGB. IV fluids $10-20 \mathrm{ml} / \mathrm{kg}$ of ringer's lactate, antibiotic and analgesic like IV paracetamol $1 \mathrm{gm}$, fentanyl $50-100 \mathrm{mcg}$, dexmeditomidine 0.3-0.5 mcg/kg were supplemented as necessary. Post block pentoxyphylline 400mg TID, Cilastozol 100mg BID, nifedipine 10mg OD and ecosprin 75 OD were continued and NSAIDs were given for 5-7 days. The patients were discharged after 24 hours of observations if associated with dry gangrene or CRPS ,some were discharged at 1-2 weeks for the reason of wound care which was taken with dressing, antibiotics or surgical debridement /partial foot/ below knee amputations in severe cases. Pre-block VAS score, WD and temperature of the limb were noted and compared with post block scores. Follow up was done every week for a month and then once a month for six months. Degree of pain relief increase in WD, changes in the temperature of toe/foot/limb noted. Incidence of immediate complications like hypotension, bradycardia, LA toxicity, allergic reaction, signs of spinal/ epidural injection or any other and late like post-dural puncture headache (PDPH), backache, weakness in the limb, lateral femoral cutaneous nerve( LFCN) or genitofemoral neuralgia (GFN) or any other till follow up at six months. Pre and post LSGB progress of wound and limb edema, colour change blackening to normal skin colour, gangrene of toes, gangrene of foot ,non-healing ulcers, amputation of toes, debridements, partial amputation of foot, below knee amputation of the limb in all the three groups observed. Progress in terms appearance of line of demarcation, regression in size of gangrene and ulcer, any need of debridement or amputation noted. Complications like neuralgias were treated with oral analgesics, steroids and gabapentinoids Statistical Analysis: We included 150 patients of PVDs of lower limb for this prospective non- randomized observational study admitted in our Institute over a period of ten years (Jan 2010 to Dec 2019) who underwent chemical LSGB-(Group CH, $n=50$ ) , RF ablation of lumbar sympathetic ganglion (Group $\mathrm{RF}, \mathrm{n}=50$ ) and combined treatment of $\mathrm{RF}+$ chemical LSGB (Group $\mathrm{RF}+\mathrm{CH}, \mathrm{n}=50$ ) LSGB and compared with each other for various parameters.

Data and graphs are prepared by using Microsoft Office Excel 2007.Statistical analysis was carried out with SPSS version 23.00. Quantitative variables like Visual Analog score-(VAS), walking distance - (WD), temperature (Temp.) were expressed as mean \pm standard Deviation (SD) and qualitative data like incidence of immediate (hypotension, bradycardia, LA toxicity, allergic reaction, signs of spinal or epidural injection or any other) and late complications (postdural puncture headache, backache, weakness in the limb, lateral femoral cutaneous nerve (LFCN) or genitor femoral neuralgia(GFN) or any other) till follow up at six months are mentioned as number and proportions /percentage. Pre and post LSGB progress of wound and limb (oedema, colour change -blackening to normal skin colour, gangrene of toes, gangrene of foot ,non-healing ulcers, amputation of toes, debridements , partial amputation of foot, below knee amputation of the limb) in patients of all the groups are also mentioned as number and proportions /percentage The $\alpha$ level for all analysis was set as $\mathrm{P}<0.05$ was considered as significant. The assessment was analysed using One Way Analysis of Variances or Kruskal-Wallis One Way ANOVA on ranks depending on the data distribution.

\section{Results}

The demographic profile is given in Table 1 . There were 150 patients of age ranging from 22years to 90 years, 16 females and 134 males having Buerger's disease $(n=56)$, atherosclerotic PVD $(n=46)$, diabetic PVD( $n=20)$, CRPS $(n=15)$, post thrombo-embolic ischemia $(n=10)$ and scleroderma associated PVD $(n=3)$ in three groups. They were subjected to chemical LSGB using $8 \%$ phenol (Group $\mathrm{CH}, \mathrm{n}=50$ ), RF ablation (Group $\mathrm{RF}, \mathrm{n}=50$ ) and combined $\mathrm{RF}$ with chemical LSGB (Group $\mathrm{RF}+\mathrm{CH}, \mathrm{n}=50$ ). Table 2 depicts the pre and post LSGB VAS scores, walking distances (WD) and Temp. in ${ }^{\circ}$ centigrade (degree $\mathrm{C}$ ) of the affected limb/foot/toe in three groups. The mean VAS score, WD and Temp. of the limb were not significantly different in all the groups $(\mathrm{CH}, \mathrm{RF}, \mathrm{RF}+\mathrm{CH}, \mathrm{P}>0.05)$. On follow up at one week of chemical neurolysis and RF treatment there was no significant difference in improved VAS (mean VAS of 3.28 in Group $\mathrm{CH}$ and 2.45 in Group RF , P>0.05) over the preblock values ( mean7.5 in Group CH,7.58in Group RF \& 7.5 in Group $\mathrm{RF}+\mathrm{CH})$.However there was significant difference in VAS scores at 6 months of follow up in Group $\mathrm{CH}$ Vs Group $\mathrm{RF}+\mathrm{CH} \&$ Group RF Vs Group $\mathrm{RF}+\mathrm{CH}$,(mean 2.2 in Group $\mathrm{CH}, 1.94$ in Group RF\& 1.26 in Group $\mathrm{RF}+\mathrm{CH}, \mathrm{P}<0.001$ ) but no significant difference when compared in Group CH Vs Group RF ( $>>0.05)$. The mean WD after 1 week of follow-up was improved in all the groups $(\mathrm{P}<0.001)$ but more significantly in $\mathrm{RF} \& \mathrm{RF}+\mathrm{CH}$ group when compared with Group CH.(WD before LSGB =mean $28.8 \mathrm{~m}$ in Group CH,31.1m in Group RF and 32.2 in Group $\mathrm{RF}+\mathrm{CH}, \mathrm{P}>0.05)$ at 1 week was $(287 \mathrm{~m}$ in Group $\mathrm{CH}, 411 \mathrm{~m}$ in Group RF,558m in Group $\mathrm{RF}+\mathrm{CH}, \mathrm{P}<0.001$ ) Later at six month follow up (mean 949 in Group CH, 1166 in Group $\mathrm{RF}$ and 1232 in Group $\mathrm{RF}+\mathrm{CH}$ ) there was significant improvement when compared to WD before LSGB $(\mathrm{P}<0.0001)$, and at six months when compared Group CH Vs Group RF and Group CH Vs Group $\mathrm{RF}+\mathrm{CH}(\mathrm{P}<0.001)$. 
Table 1: Demographic profile of the patients with PVDs. Comparison of three groups (Chemical-Group $\mathrm{CH}$, Radiofrequency Ablation-Group RF, combined-Group RF +CH).

\begin{tabular}{|c|c|c|c|c|c|c|c|c|}
\hline & $\mathbf{M} / \mathbf{F}$ & Age range & $\begin{array}{l}\text { Buerger's disease } \\
\text { with h/o smoking }\end{array}$ & $\begin{array}{l}\text { Atheros- } \\
\text { clerotic PVD }\end{array}$ & Diabetic PVD & CRPS & $\begin{array}{c}\text { Post } \\
\text { thrombo- } \\
\text { embolic }\end{array}$ & Sclero-derma \\
\hline $\begin{array}{l}\text { Group CH } \\
(\mathrm{n}=50)\end{array}$ & $45 / 5$ & 42-85yrs & 20 & 7 & 11 & 7 & 3 & 2 \\
\hline Group RF(n=50) & $46 / 4$ & $25-75 y r s$ & 18 & 20 & 5 & 3 & 4 & 0 \\
\hline $\mathrm{RF}+\mathrm{CH}(\mathrm{n}=50)$ & $43 / 7$ & $22-90 y r s$ & 18 & 19 & 4 & 5 & 3 & 1 \\
\hline
\end{tabular}

Table 2: Pre and post lumbar sympathetic block(LSGB) observations: (Visual Analog score-VAS, walking distance in meters -WD, temperature in degrees $\mathrm{C}$ (Temp.) of the affected limb) Comparison of three groups (Chemical-Group $\mathrm{CH}$, Radiofrequency ablationGroup RF, combined-Group RF +CH).

\begin{tabular}{|c|c|c|c|c|}
\hline & Group CH LSGB $(n=50)$ & Group RF (n=50) & Group RF +CH $(n=50)$ & P Value One way (ANOVA) \\
\hline \multirow{2}{*}{ VAS before LSGB } & \multirow{2}{*}{$7.5 \pm 0.8631$} & \multirow{2}{*}{$7.58 \pm 0.8593$} & \multirow{2}{*}{$7.5 \pm 0.8631$} & Kruskal- Wallis test $\mathrm{P}=0.8664, \mathrm{P}>0.05$ (NS) \\
\hline & & & & For all three groups $(\mathrm{CH}, \mathrm{RF}, \mathrm{RF}+\mathrm{CH})$ \\
\hline \multirow{4}{*}{$\begin{array}{l}\text { VAS after chemical LSGB } \\
\text { block at } 1 \text { week Mean } \pm \text { SD }\end{array}$} & \multirow{4}{*}{$3.280 \pm 0.888888816$} & \multirow{4}{*}{$3.400 \pm 0.699$} & \multirow{4}{*}{$2.440 \pm 0.6749$} & $\begin{array}{c}\text { Kruskal-Wallis test KW }=37.510, \mathrm{P}<0.0001 \\
\text { (ES) }\end{array}$ \\
\hline & & & & CH Vs RF, $P>0.05$, (NS) \\
\hline & & & & CH Vs RF $+\mathrm{CH}, \mathrm{P}<0.001,(\mathrm{~S})$ \\
\hline & & & & RF Vs RF $+\mathrm{CH}, \mathrm{P}<0.001,(\mathrm{~S})$ \\
\hline \multirow{4}{*}{$\begin{array}{l}\text { VAS at } 6 \text { month after } \\
\text { chemical LSGB Mean } \pm \text { SD }\end{array}$} & \multirow{4}{*}{$2.200 \pm 0.8081$} & \multirow{4}{*}{$1.940 \pm 0.7398$} & \multirow{4}{*}{$1.260 \pm 0.6328$} & $\begin{array}{c}\text { Kruskal-Wallis test } \mathrm{KW}=54.671, \mathrm{P}<0.0001 \\
(\mathrm{ES})\end{array}$ \\
\hline & & & & CH Vs RF P>0.05 \\
\hline & & & & CH Vs RF + CH P $<0.001$ \\
\hline & & & & RF Vs RF + CH P $<0.001$ \\
\hline \multirow{3}{*}{$\begin{array}{l}\text { WD before LSGB, Mean } \\
\pm \text { SD }\end{array}$} & \multirow{3}{*}{$28.8 \pm 6.273$} & \multirow{3}{*}{$31.1 \pm 8.823$} & \multirow{3}{*}{$32.2 \pm 8.758$} & Kruskal-Wallis test \\
\hline & & & & $\mathrm{KW}=4.576$ \\
\hline & & & & $\mathrm{P}=0.1014(\mathrm{NS})$ \\
\hline \multirow{5}{*}{$\begin{array}{l}\text { WD after chemical LSGB at } \\
1 \text { week Mean } \pm \text { SD }\end{array}$} & \multirow{2}{*}{$286.6 \pm 125.82$} & \multirow{2}{*}{$411 \pm 145.44$} & \multirow{2}{*}{$558 \pm 124.69$} & Kruskal-Wallis test $\mathrm{KW}=63.973$ \\
\hline & & & & $\mathrm{P}<0.001(\mathrm{~S})$ \\
\hline & 0.1776 & 0.1301 & 0.1791 & CH Vs RF, $\mathrm{P}<0.001$ (S) \\
\hline & \multirow{2}{*}{0.0004} & \multirow{2}{*}{0.0338} & \multirow{2}{*}{0.0004} & $\mathrm{CH}$ Vs $\mathrm{RF}+\mathrm{CH} \mathrm{P}<0.001(\mathrm{~S})$ \\
\hline & & & & RF VS RF+CH P<0.001 (S) \\
\hline \multirow{5}{*}{$\begin{array}{l}\text { WD at } 6 \text { month after } \\
\text { chemical LSGB Mean } \\
\text { (SD) Normality test KS } \\
\text { Normality test P value }\end{array}$} & \multirow{3}{*}{$949 \pm 246.92$} & \multirow{3}{*}{$1166 \pm 216.29$} & \multirow{3}{*}{$1232 \pm 02.47$} & Kruskal-Wallis test KW=39.826 \\
\hline & & & & $\mathrm{P}<0.0001$, (ES) \\
\hline & & & & CH Vs RF P<0.001(S) \\
\hline & 0.218 & 0.1786 & 0.2028 & CH Vs RF+CH P<0.001(S) \\
\hline & $\mathrm{P}<0.0001$ & $\mathrm{P}=0.004$ & $\mathrm{P}<0.0001$ & RF Vs RF+CH P>0.05 (NS) \\
\hline \multirow{3}{*}{$\begin{array}{l}\text { Temp. of the affected limb } \\
\text { before LSGB (degrees C), } \\
\text { Mean } \pm \text { SD }\end{array}$} & \multirow{3}{*}{$29.958 \pm 1.265$} & & & Kruskal-Wallis test $\mathrm{KW}=1.845$ \\
\hline & & $29.164 \pm 1.403$ & $29.786 \pm 1.248$ & $\mathrm{P}=0.3975,(\mathrm{NS})$ \\
\hline & & & & For all the three groups $(\mathrm{CH}, \mathrm{RF}, \mathrm{RF}+\mathrm{CH})$ \\
\hline Temp. rise (degrees C) & & & & Kruskal-Wallis test $\mathrm{KW}=2.142$ \\
\hline $\begin{array}{l}\text { in affected limb after } \\
\text { chemical LSGB at } 1 \text { week, }\end{array}$ & $1.6 \pm 0.3709$ & $1.686 \pm 0.3959$ & $1.602 \pm 0.3706$ & $\mathrm{P}=0.3426,(\mathrm{NS})$ \\
\hline Mean \pm SD & & & & For all the three groups $(\mathrm{CH}, \mathrm{RF}, \mathrm{RF}+\mathrm{CH})$ \\
\hline & & & & Kruskal-Wallis test $\mathrm{KW}=7.141$ \\
\hline Temp. rise (degrees C) & & & & $\mathrm{P}=0.0281,(\mathrm{~S})$ \\
\hline $\begin{array}{l}\text { in the affected limb at } \\
6 \text { month after chemical }\end{array}$ & $2.622 \pm 0.2243$ & $2.7 \pm 0.2828$ & $2.756 \pm 0.2620$ & CH Vs RF P>0.05 (NS) \\
\hline Mean \pm SD & & & & $\mathrm{CH}$ Vs $\mathrm{RF}+\mathrm{CH} \mathrm{P}<0.05(\mathrm{~S})$ \\
\hline & & & & RF Vs RF+CH P>0.05 (NS) \\
\hline
\end{tabular}




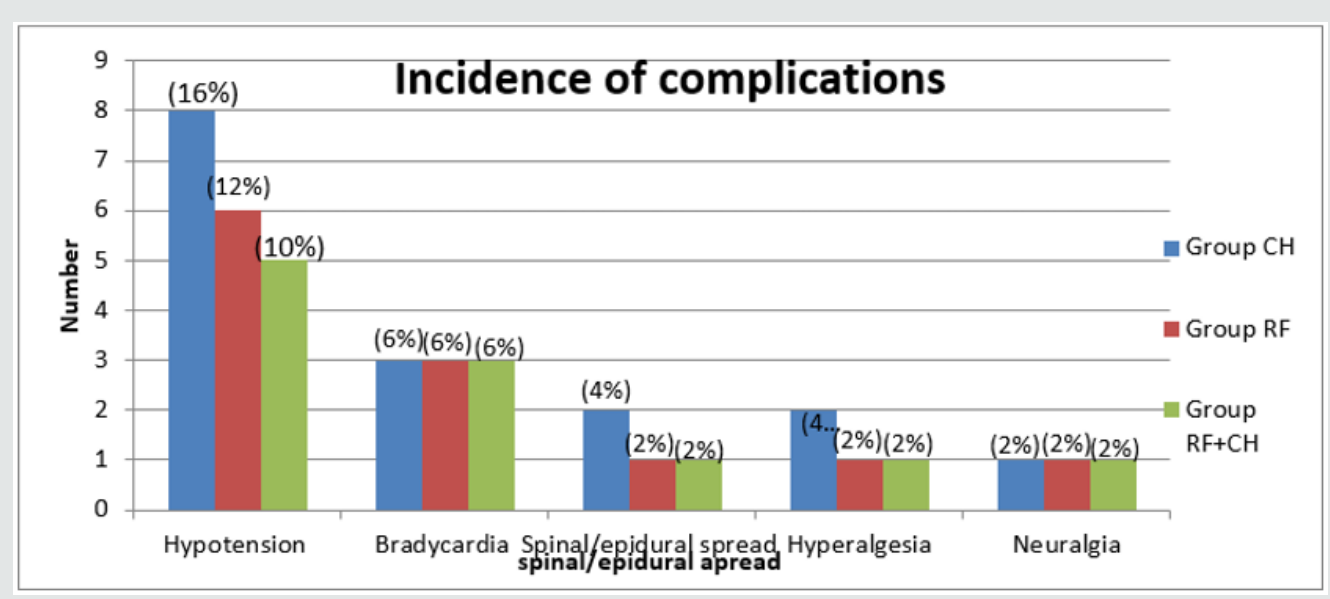

Graph 1: Incidence of immediate (hypotension, bradycardia, LA toxicity, allergic reaction, signs of spinal or epidural injection or any other)and late complications (post-Dural puncture headache, backache, weakness in the limb, lateral femoral cutaneous nerve (LFCN) or genitofemoral neuralgia (GFN) or any other till follow up at 6 months) Comparison of three groups (ChemicalGroup $\mathrm{CH}$, Radiofrequency ablation-Group RF, combined-Group RF $+\mathrm{CH}$ ). Values in number \& percentage $\%$.

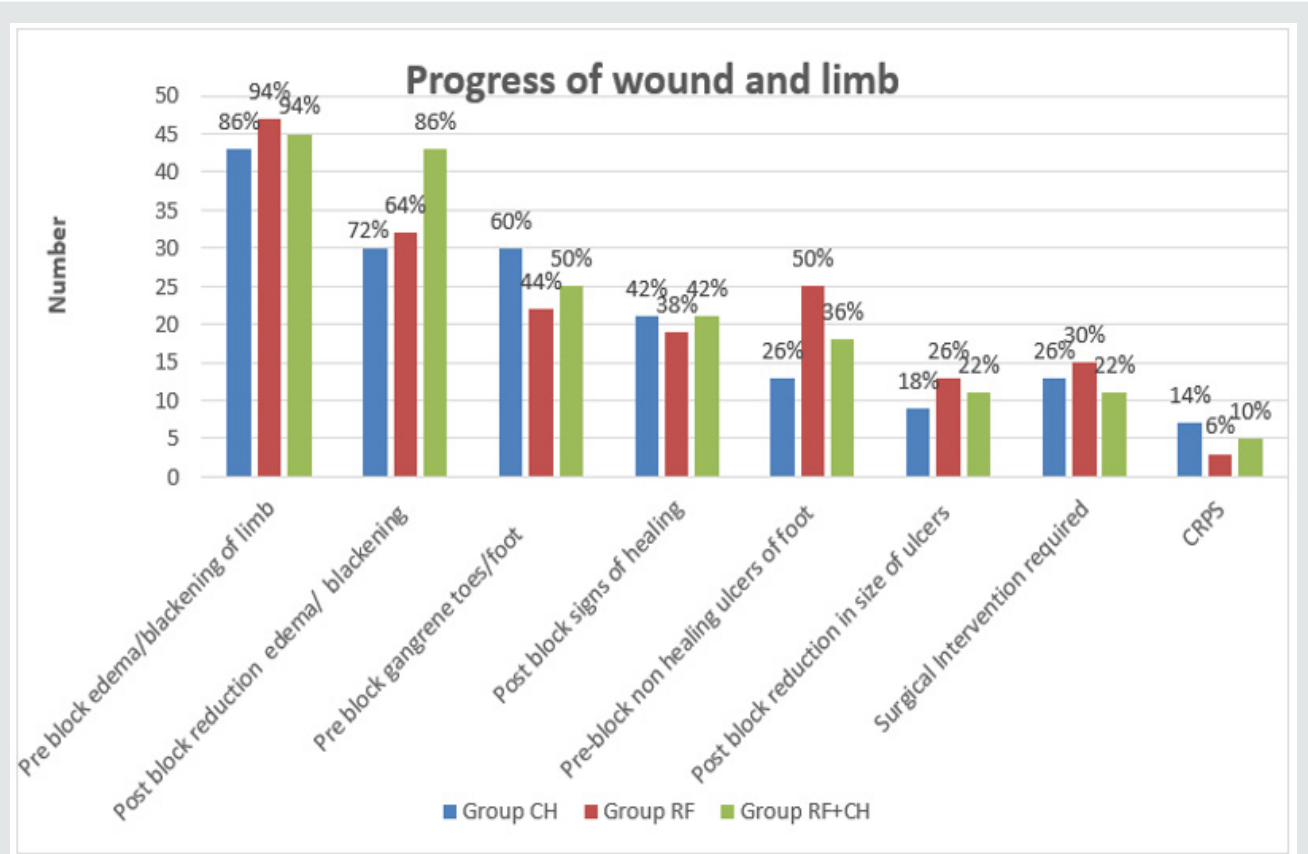

Graph 2: Pre and post LSGB progress of wound and limb (edema, colour change -blackening to normal skin colour, gangrene of toes, gangrene of foot ,non-healing ulcers, amputation of toes, debridements, partial amputation of foot, below knee amputation of the limb) Comparison of three groups (Chemical-Group $\mathrm{CH}$, Radiofrequency ablation-Group RF, combinedGroup $\mathrm{RF}+\mathrm{CH})$. Values in number \& \%.

The improvement in WD was comparable in Group RF and $\mathrm{RF}+\mathrm{CH}(\mathrm{P}>0.05)$. Baseline Temp. of the affected limb/toe before LSGB was mean 29.9 in Group CH, 29.2 in Group RF and $29.8^{\circ} \mathrm{C}$ in Group $\mathrm{RF}+\mathrm{CH}$ with no difference amongst all the groups $(\mathrm{P}>0.05)$. At one week of LSGB there was significant rise in temperature of the affected limb /toe in all the groups when compared with $\mathrm{CH}$ $\mathrm{V}$ RF,CH Vs $\mathrm{RF}+\mathrm{CH}$ and $\mathrm{RF}$ Vs $\mathrm{RF}+\mathrm{CH}$ ( mean rise of 1.6 in Group $\mathrm{CH}, 1.69$ in Group $\mathrm{RF}$ and $1.6{ }^{\circ} \mathrm{C}$ in Group $\mathrm{RF}+\mathrm{CH}(\mathrm{P}>0.05)$. At six months of follow up the Temp. rise noted was 2.6 in Group $\mathrm{CH}$, 2.76 in Group $\mathrm{RF}$ and $2.76{ }^{\circ} \mathrm{C}$ in Group $\mathrm{RH}+\mathrm{CH}$ which showed no significant difference if compared in Group $\mathrm{CH}$ Vs $\mathrm{RF}$ and Group RF Vs $\mathrm{RF}+\mathrm{CH}, \mathrm{P}>0.05$. Howevere the difference in Temp. rise was significant at six months when compared the Group $\mathrm{CH}$ Vs $\mathrm{RF}+\mathrm{CH}, \mathrm{P}<0.05$. (Graph 1) Shows the Incidence of immediate and late complications till follow up at six months in three groups $(\mathrm{CH}, \mathrm{RF}, \mathrm{RF}+\mathrm{CH})$ in values as number (\%).Immediate complications occurred like hypotension in 8(16\%),6(12\%), 5(10\%) and bradycardia in 3(6\%),3(6\%),3(6\%) cases after LSGB in Groups $\mathrm{CH}$, $\mathrm{RF}, \mathrm{RF}+\mathrm{CH}$ respectively. They were managed with fluid boluses, small doses of vasopressors and anticholinergics glycopyrrolate or 
atropine in appropriate doses. Post block signs of spinal/epidural spread observed in 2(4\%), 1(2\%), $1(2 \%)$ in Groups $\mathrm{CH}, \mathrm{RF}, \mathrm{RF}+$ $\mathrm{CH}$. All of them responded to fluids and bed rest. Hyperalgesia in the affected, limb/toe was noted in $2(4 \%), 1(2 \%)$ and $1(2 \%)$ of Group $\mathrm{CH}, \mathrm{RF}, \mathrm{RF}+\mathrm{CH}$ respectively after block late. complication like neuralgia after the LSGB treatment observed in $1(2 \%, \mathrm{GFN})$, $1(2 \%, \mathrm{LFCN}), 1(2 \%, \mathrm{LFCN})$ of Groups $\mathrm{CH}, \mathrm{RF}, \mathrm{RF}+\mathrm{CH}$ respectively that was managed with analgesics and gabapentinoids. (Graph 2) demonstrates pre and post LSGB progress of wound and limb. Values in number (\%) Pre block edema/ blackening of skin of the limb was present in 43 (86\%), 47 (94\%),45 (90\%) of patients of Groups $\mathrm{CH}$, $\mathrm{RF}, \mathrm{RF}+\mathrm{CH}$ respectively where response to the LSGB was seen in $30(60 \%), 32(64 \%), 43(86 \%)$ of Groups $\mathrm{CH}, \mathrm{RF}, \mathrm{RF}+\mathrm{CH}$ respectively .Gangrene of toes/foot was present in 30(60\%), 22(44\%), 25(50\%) and improvement was seen in 21(42\%), 19(38\%), 21(42\%) of cases of Groups $\mathrm{CH}, \mathrm{RF}, \mathrm{RF}+\mathrm{CH}$ respectively. Non-healing ulcers were present in 13(26\%), 25(50\%), 18(36\%) and good response was seen in 9(18\%), 13(26\%), 11(22\%) of Groups $\mathrm{CH}, \mathrm{RF}, \mathrm{RF}+\mathrm{CH}$ patients respectively.

In Group CH Interventions required in 13(26\%) cases (6 (12\%) cases needed debridement of wounds,3(6\%) cases needed partial amputation of foot,4 (8\%) cases required below knee amputation. In Group RF intervention required in 15 (30\%) cases, debridement's in $8(16 \%)$ cases, partial amputation in $6(12 \%)$ cases, and below knee amputation in $4(8 \%)$ cases. In Group $\mathrm{RF}+\mathrm{CH}$ intervention in $11(22 \%)$ cases (debridement in 5(10\%) cases, partial amputation in $4(8 \%)$ cases, below knee amputation in $2(4 \%)$ cases. Incidence of CRPS was $7(14 \%), 3(6 \%), 5(10 \%)$ of Groups $\mathrm{CH}, \mathrm{RF}, \mathrm{RF}+\mathrm{CH}$ patients respectively. In Group CH 7(14\%) CRPS cases had 75\% relief in pain and swelling at three month and $90 \%$ at six months of follow up. In Group RF $100 \%$ relief in 2(4\%) at three and sixmonth $1(2 \%)$ case had $50 \%$ relief at $3 \& 6$ month follow up. In Group RF+CH 3(6\%) cases had 90\% relief at 3\& 6month 2 (4\%) had $75 \%$ relief at $3 \& 6$ month of follow up. Discussion Felix Mandl first described the Selheim's technique of lumbar sympathetic plexus block in 1924. He used 6\% phenol at cervical ganglion in cats and suggested phenol for permanent sympathectomy [14,15]. Currently radiofrequency (RF) ablation of sympathetic ganglion is considered to be safe and effective option but have concerns of availability and high cost of treatment. Hence chemical neurolysis is still a popular method in most of the pain management centres [16-18].

Radiofrequency therapy has two modes pulsed radiofrequency and thermocoagulation which targets nerve tissue by increasing temperature where unmyelinated $\mathrm{C}$ nerve fibres get dissolved and become necrotic resulting in vasodilatation in lower extremities and long-term pain relief improves numbness of neuropathies. However, accuracy of targeted structure is extremely difficult, and range of ablation is limited [12,19]. Manjunath et al [13] conducted a pilot study on 20 patients of CRPS type-I to compare the chemical neurolysis with $7 \%$ phenol and RF lumbar sympathectomy.
Significant pain relief was present in both the groups without significant difference in mean pain scores between the groups [13]. Singh et al. conducted fluroscopic guided lumbar chemical sympathectomy using $8 \%$ phenol $8 \mathrm{ml}$ at L3 and L4 level following six successive blocks with LA in fifteen patients suffering from Beurger's disease with gangrene of toes. Significant improvement in VAS scores, WD and healing of toes observed in all the patients with each successive block. Thus, he concluded that lumbar sympathetic block is very cost effective, safe and least invasive method for painful ischemic leg ulcers [20]. As the Buerger's disease progresses it results in amputation of gangrenous toes or limbs eventually leading to persistent post amputation pain and disability. Fifty such patients were studied by Usmani et al. [21] with chemical lumbar sympathectomy $(\mathrm{n}=25)$ and found significant reduction in development of phantom limb pain, VAS score, quality of life compared to control group ( $\mathrm{n}=25$ ) [21] Recently combined chemical neurolysis and radiofrequency ablation of lumbar sympathetic ganglion is also studied in PVDs with diabetic techniques but there are limited studies to establish significant advantage of prolonged effects with RF over chemical neurolysis [10,13]. Hence combined methods are studied as by Dhafir A et al. [12] who used pulsed RF with phenol at three levels $(L 2,3,4)$ for lumbar sympathectomy in a case of CRPS and found satisfactory result [10]. Yuanyuan Ding et al. [7] conducted comparative study with CT guided chemical Vs RF Vs RF with chemical (anhydrous ethanol) lumbar sympathectomy at L2 \&L3, for 30 patients in each group in patients with diabetic peripheral neuropathy and found it safe effective with better results in terms pain relief and duration and patients satisfaction in combined treatment group (RF+ chemical) [13] .We too observed improvement inVAS scores, WD and Temp. rise at one week in all the groups when compared with values before the LSGB. However at six months of follow up significant difference in VAS Group $\mathrm{CH}$ Vs Group $\mathrm{RF}+\mathrm{CH}$ and Group RF Vs Group $\mathrm{RF}+\mathrm{CH}$, (mean VAS 2.2 in Group CH, 1.94 in Group RF\& 1.26 in Group RF+CH,P $<0.001$ ). The mean WD improved significantly at six months more in Group RF and $\mathrm{RF}+\mathrm{CH}$ when compared with Group $\mathrm{CH}$ (mean 949 in Group CH, 1166 in Group RF and 1232 in Group $\mathrm{RF}+\mathrm{CH}, \mathrm{P}<0.001)$. At six months the Temp. rise in affected limb/toe noted (2.6 in Group CH, 2.76 in Group RF and $2.76^{\circ} \mathrm{C}$ in Group RH $12+\mathrm{CH}$ ), was significant for Group $\mathrm{CH}$ Vs $\mathrm{RF}+\mathrm{CH}, \mathrm{P}<0.05$. The incidences of immediate and late complications were similar in all the groups. There was good response to the treatment in all the groups but more satisfactory in combined LSGB patients when observed for the course of wound healing following LSGB.

In Group CH all CRPS (7) cases had 90\% relief in pain at six months of follow up. In Group RF $100 \%$ relief in two at six-month, one case had 50\% relief at six month follow up. In Group $\mathrm{RF}+\mathrm{CH}$ three cases had $90 \%$ relief at six months, two had $75 \%$ relief at six months of follow up. Besides Temp. measurement other objective tests like ankle/brachial (ABI), sympathetic skin response (SSR) in response to application of a sensory stimulation using EMG 
machine. Thus provocative tests like sweat chloride tests, SSR test and vibratory perception threshold over affected toes and external malleolus of both sides are methods of objective assessment [2224].Infrared thermographic imaging and transcutaneous oxygen tension $\left(\mathrm{TcPO}_{2}\right)$.Each test has specific utility and can be used in combination to obtain information about functional severity of PVD in patients with claudication. $[25,26]$ Rooke et al. evaluated influence of sympathetic activity on $\mathrm{TcPO}_{2}$ in ischemic limb. They measured dorsal foot $\mathrm{TcPO}_{2}$ by oxygen-sensing electrodes with surface temperatures of 42 degree $\mathrm{C}$ and $45^{\circ} \mathrm{C}$. The vasodilatation Index $\mathrm{TcPO}_{2}$ at $42{ }^{\circ} \mathrm{C} / \mathrm{TcPO}_{2}$ at $45{ }^{\circ} \mathrm{C}$ as an index of vasomotor tone was measured in normal, ischemic limb and after cooling the limb and concluded that $\mathrm{TcOP}_{2}$ can be used to assess the degree of vasomotor tone in the skin that increases as ischemia worsens. Warmth improves the cutaneous circulation in ischemic limbs [27] Angiography has been used but difficult to predict the response. Doppler ultrasound can determine the pressure in the thigh and ankle. Ankle systolic pressure above $60 \mathrm{mmHg}$ and $\mathrm{ABI}>0.3$ and patency of superficial femoral artery found to be successful predictive test.

High correlation is observed between $\mathrm{ABI}$ and $\mathrm{TcPO}_{2}$. Transmetatarsal $\mathrm{TcPO}_{2}<30 \mathrm{mmHg}$ may result in amputation [28].The patients suffering from CRPS who are refractory to conventional treatment or chemical/ RF ablation, spinal cord stimulation is recommended to improve pain and dysfunction [29]. With the introduction of ultrasound (USG) many benefits like avoidance of radiation of fluoroscopy, prevention of vascular injection by visualizing the spread of injectate with real time US scan thus reducing the procedure time. Ryu et al conducted USG Vs fluoroscopy guided LSGB in fifty patients of PVDs with sympathetically mediated pain. Procedure time and success rate were not significantly different in two groups although procedural time was longer with USG technique, but onset time was faster. [30] The newer modalities like spinal cord stimulation or surgical revascularization are claimed to better outcomes but at present very costly and beyond reach of many centres [31]. limitation of the study by Explanation: The chemical neurolysis and RF are established techniques, so this prospective observational study was conducted. As the availability of radiofrequency machine was not sure hence, we could not randomize the patients for three different modalities of the treatment for comparison of the efficacy with chemical, RF and RF with chemical. The type of wounds, time of presentation and difference in associated pathologies in groups of patients, we have not compared the outcome in terms of progress in healing and surgical interventions done. More studies are required with similar comparisons to support the usefulness of combined method of RF+ chemical over sole RF or chemical LSGB.

\section{Conclusion}

We observed significant reduction in VAS score, increase in WD and rise in Temp. of the limb in all the groups, but longer lasting effects seen in combined technique i.e.in Group $\mathrm{RF}+\mathrm{CH}$ as compared to sole RF or chemical LSGB. The course of the disease was similar and satisfactory in all the groups.

\section{Conflict of Interest}

The authors declare that there is no conflict of interest regarding the publication.

\section{Source of Support}

The Research work is partially funded by D Y Patil Medical College and University, Kolhapur (MH) India. (Letter No. DYPU/2014/112)

\section{Acknowledgement}

We acknowledge the support of Department of Surgery, D Y Patil Medical College \& University while publishing this article.

\section{References}

1. Boas RA, Hatangdi VS, Richards EG (1976) Lumbar sympathectomy: A percutaneous chemical technique. Adv Pain Res Ther 1: 685.

2. Richard Rauck. Sympathetic Nerve Blocks: Head, Neck and trunk. In P Prithvi Raj. Practical Management of Pain. MOSBY, INC ( $3^{\text {rd }}$ Edn) pp.673678.

3. Fyfe T, Quin RO (1975) Phenol sympathectomy in the treatment of intermittent claudication: a controlled clinical trial. Br J Surg 62: 68-71.

4. Herman BE, Dworecka F, Wisham L (1970) Increase of dermal blood flow after sympathectomy as measured by radioactive sodium uptake. Vasc Surg 4: 161-166.

5. Christopher J (1981) Aspects of Treatment. Chemical lumbar sympathectomy with Radiological assessment. Annals of the Royal College of Surgeons of England 63: 420-422.

6. Waldman SD, Winnie AP (1996) Interventional Pain Management Philadelphia, WB Saunders.

7. Yuanyuan Ding, Peng Yao, hongxi li, Rongjie Zhao, guangyi Zhao (2018) Evaluation of combined radiofrequency and chemical blockade of multisegmental lumbar sympathetic ganglia in painful diabetic peripheral neuropathy. Journal of Pain Research 11: 1375-1382.

8. Reid W, Watt JK, Gray TG (1970) Phenol injection of the sympathetic chain. Br J Surg 57: 45-50.

9. Pernak, J (1988) Percutaneous radiofrequency thermal lumbar sympathectomy and its clinical use. Eburon.

10. Haynsworth RF Jr, Noe CE (1991) Percutaneous lumbar sympathectomy: A comparison of radiofrequency denervation versus phenol neurolysis. Anesthesiology 74: 459-463.

11. Kline MT, Yin W (2001) Radiofrequency techniques in clinical practice. In: Waldman SD, editor. Interventional pain management ( $\left.2^{\text {nd }} E d n\right)$. Philadelphia: W.B. Saunders pp. 243-293.

12. Dhafir A Alkhudhairi, Mohamed M Hashim, Ahmed A Oriba, Iftikhar Ali (2013) Complete Pain Relief after Combining Radiofrequency and Phenol for Lumbar Sympathectomy. Bahrain Medical Bulletin 35(1).

13. Manjunath PS, Jayalakshmi TS, Dureja GP, et al. (2008) Management of Lower Limb Complex Regional Pain Syndrome Type 1: An Evaluation of Percutaneous Radiofrequency Thermal Lumbar Sympathectomy Versus Phenol Lumbar Sympathetic Neurolysis--A Pilot Study. Anesth Analg 106(2): 647-649.

14. Brunn F, Mandl F (1924) Die Paravertebral Injection. ZurBekaempfungvisceralerSchmerzen. WienKlinAschsch 37: 511. 
15. Huang J (2002) Letter to the Editor: The History Of Chemical Lumbar Sympathectomy. The Internet Journal of Anesthesiology 7: 1.

16. Kha Tran, Steven Frank, Srinivasa Raja, Hossam El-Rahmany, Lauren Kim, et al. (2000) Lumbar sympathetic block for sympathetically maintained pain: Changes in cutaneous temperatures and pain perception. Anaesth Analg 90(6): 1396-1401.

17. Bhattarai BK, Rahman TR, Biswas BK, Sah BP, Agarwal B (2006) Fluoroscopy guided chemical lumbar sympathectomy for lower limb ischaemic ulcers. JNMA 45: 295-299.

18. Agarwal P, Sharma D (2009) Lumbar Sympathectomy Revisited: Current Status in Management of Peripheral Vascular Diseases. The Internet Journal of Surgery 18(1): 1-5.

19. Manchikanti L (2000) The role of radiofrequency in the management of complex regional pain syndrome. Curr Rev Pain 4(6): 437-444.

20. Rampal Singh, Aparna Shukla, Lakhwinder Singh Kang, Anand Prakash Verma (2014) Chemical lumbar sympathetic plexus block in buerger's disease: Current scenario. Indian Journal of Pain 28 (1): 24-28.

21. Usmani H, Hasan M, Alam MR, Harris SH, Mansoor T, et al. (2016) Effect of preamputation lumbar sympathectomy on stump pain of lower limbs in patients of thrombo angitisobliterans (Buerger's disease). Indian J Pain 30: 132-137.

22. Stevens RA, Stotz A, Kao TC, Powar M, Burgess S, et al. (1998) The relative increase in skin temperature after stellate ganglion block is predictive of a complete sympathectomy of the hand. Reg Anesth Pain Med 23: 266-270.
23. Schmid MR, Kissling RO, Curt A, Jaschko G, Hodler J (2006) Sympathetic skin response: Monitoring of CT-guided lumbar sympathetic blocks. Radiology 241: 595-602.

24. Park SY, Nahm SG, Kim YC, Lee SC (2009) The cutoff rate of temperature to interpret the successful lumbar sympathetic block. The Korean Pain Society The forty-nine Scientific Meeting (11), Seoul.

25. Kim YC, Bahk JH, Lee SC, Lee YW (2003) Infrared thermographic imaging in the assessment of successful block on lumbar sympathetic ganglion. Yonsei Med J 44: 119-124.

26. Creager MA (1997) Clinical assessment of the patient with claudication: the role of the vascular laboratory. Vasc Med 2(3): 231-237.

27. Rooke TW, Hollier LH, Osmundson PJ (1987) The influence of sympathetic nerves on transcutaneous oxygen tension in normal and ischemic lower extremities. Angiology 38(5): 400-410.

28. Van Eijs F, Stanton-Hicks M, Van Zundert J, et al. “Complex regional pain syndrome." Pain Practice 11(1): 70-87.

29. Ryu JH, Lee CS, Kim YC, Lee SC, Shankar H, et al. (2018) Ultrasoundassisted versus fluoroscopic-guided lumbar sympathetic ganglion block: A prospective and randomized study. Anesth Analg 126: 1362-1368.

30. Kumar K, Toth C, Nathr K, Vermaa K, Burgess JJ (1997) Improvement of limb circulation in peripheral vascular disease using epidural spinal cord stimulation in prospective study. J Neurosurg 86: 662-699.

31. Mekhail NA, Mathews M, Nageeb F, Guirguis M, Mekhail MN, et al. (2011) "Retrospective review of 707 cases of spinal cord stimulation: indications and complications." Pain Practice 11(2): 148-153.

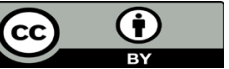

This work is licensed under Creative Commons Attribution 4.0 License

To Submit Your Article Click Here: Submit Article

DOI: $10.32474 /$ GJAPM.2020.03.000163

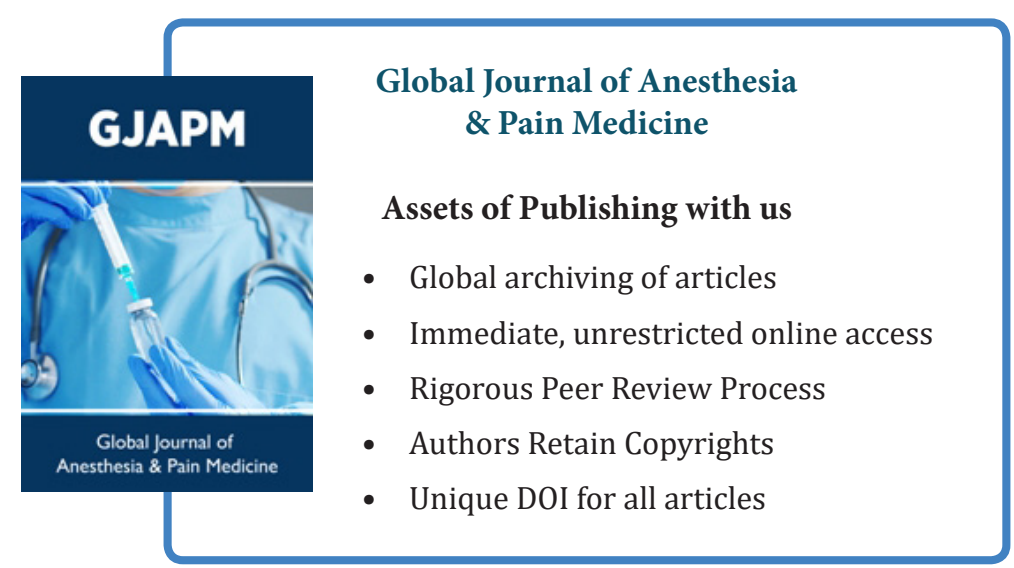

